13. Шорин А.Ф. О двух новых вариантах неолитической керамики козловского и боборыкинского типов по материалам Кокшаровского холма // Проблема изучения неолита Западной Сибири. Тюмень: Изд-во ИПОС СО РАН, 2001. С. 154-161.

14. Жилин М.Г., Антипина Т.Г., З Зарецкая Н.Е., Косинская Л.Л., Косинцев П.А., Иванова Н.К., Савченко С.Н., Успенская О.Н., Чаиркина Н.М. Варга 2. Ранненеолитическая стоянка в Среднем Зауралье (опыт комплексного анализа). Екатеринбург: Режевской печатный дом, 2007. 98 с.

15. Герасименко А.А. Характеристика керамики поселения Евстюниха I // Вопросы археологии Урала: сборник научных трудов.Вып. 25. Екатеринбург; Сургут: Магеллан, 2008. С. 44-72.

16. Бунькова А.А. Радиоуглеродные даты с поселений Евстюниха I и Полуденка I // Вопросы археологии Урала: сборник научных трудов. Вып. 26. Екатеринбург; Сургут: Магеллан, 2011. С. 236.
17. Кернер В.Ф. Поселение Исетское Правобережное // Неолитические памятники Урала. Свердловск: Уральский рабочий, 1991. С. 46-67.

18. Ковалева В.Т., Зырянова С.Ю. Продолжение дискуссии о зауральском неолите // Вопросы археологии Урала: сборник научных трудов. Вып. 25. Екатеринбург; Сургут: Магеллан, 2008. С. 30-43.

19. Стефанова Н.К. Исток IV - неолитический памятник Тюменского Притоболья // Неолитические памятники Урала. Свердловск: Уральский рабочий, 1991. С. 132-143.

Исследование выполнено в рамках научно-исследовательской программы «Древние и средневековые культуры Урала: региональные особенности в контексте глобальных процессов" и при финансовой поддержке РФФИ, проект № 18-09-00040 «Корреляция хронологии неолитических культур степной, лесостепной и лесной зон от Дона до Иртыши».

\title{
EARLY NEOLITHIC OF TRANS-URALS: THE CONTEMPORARY VIEW ON HISTORIOGRAPHIC PROBLEMS
}

(C) 2019

Mosin Vadim Sergeevich, doctor of historical sciences,

director; leading researcher of Eurasian Studies Research and Education Centre

South-Ural Branch of Institute of History and Archaeology

of Ural Branch of Russian Academy of Sciences (Chelyabinsk, Russian Federation);

South Ural State University (National Research University) (Chelyabinsk, Russian Federation)

Yakovleva Ekaterina Sergeevna, postgraduate student of Archeology and Ethnography Department

South-Ural Branch of Institute of History and Archaeology of Ural Branch of Russian Academy of Sciences (Chelyabinsk, Russian Federation)

Abstract. This paper is devoted to the critical issues of historiography and source study in the early Neolithic of the Trans-Urals. The authors consider basic dated monuments in the context of radiocarbon chronology; analyze the established criteria for identifying archaeological cultures and ceramic traditions and types of this period. Based on statistical processing of the ceramics of the forest-steppe Tobol region settlements: Tashkovo 1, Dolgovskoe 3, Kochegarovo 1, Ust-Suerka 4, the authors distinguish some stadial features in the evolving of the material culture of the early Neolithic in the first and second halves of 6 thousand BC. Attention is paid, firstly, to the co-existence of Koshkino and Kozlovo ancientries within the settlements, and, secondly, to the coincidence of a number of characteristics of Koshkino and Kozlovo material culture regarding the morphology of potteries, ornamentation techniques and basic decorative motifs. Within the framework of a sociocultural approach, it is proposed to consider the bodies of evidence as complexes of two coexisting and interacting traditions within one sociocultural space, understood in the source sense as an archaeological culture, instead of dividing them into two independent lines of development. Besides it is emphasized that the problem of the Neolithization of Trans-Urals, on the basis of the available data, at this time cannot be solved plausible.

Keywords: historiography; early Neolithic; Trans-Urals and forest-steppe Tobol region; radiocarbon chronology; Koshkino tradition; Kozlovo tradition; Koksharovsko-Yurinsky type; Evstyunichsky type; ceramic signs; cultural and chronological scheme; sociocultural approach; Neolithization.

УДК $7.031(470.5)$

DOI 10.24411/2309-4370-2019-12216

Статья поступила в редакцию 27.01.2019

\section{ОБРАЗ ВОДОПЛАВАЮЩЕЙ ПТИЦЫ В ИСКУССТВЕ НЕО-ЭНЕОЛИТИЧЕСКОГО НАСЕЛЕНИЯ УРАЛА}

(C) 2019

Сериков Юрий Борисович, доктор исторических наук, ведущий научный сотрудник археологической лаборатории Нижнетагильский государственный соичально-педагогический институт (филиал) Российского государственного профессионально-педагогического университета (2. Нижний Тагил, Свердловская область, Российская Федеращия)

Аннотащия. Первая обобщающая работа об изображениях водоплавающей птицы в неолитическом искусстве представлена Н.Н. Гуриной в 1972 г. На основании многочисленных находок автор определяет их хронологию и территорию распространения, характеризует особенности изображений и предлагает реконструкцию общей картины мира. При этом Урал является самым восточным районом распространения изображе- 
ний водоплавающей птицы, отмеченный лишь немногочисленными находками. К настоящему времени представленная Н.Н. Гуриной ситуация сильно изменилась. На территории Урала выявлены десятки скульптурных изображений водоплавающих птиц эпохи неолита и энеолита, изготовленные из камня, глины, кости, рога, дерева. Еще больше известно гравированных изображений птиц на керамических сосудах. Практически все сосуды относятся к энеолитическому времени. По мнению уральских археологов, образ птицы выступал в разных символических значениях: птица считалась основным персонажем в творении мира; она могла выступать в качестве первопредка, прародительницы рода; птица связана со становлением промыслового культа; она могла отражать календарную символику. Подтверждается предположение Н.Н. Гуриной, что территория распространения изображений водоплавающей птицы совпадает с областью проживания населения финно-угорской языковой группы.

Ключевые слова: Урал; водоплавающая птица; утка; гусь; лебедь; гагара; болотная курочка; неолит; энеолит; скульптурные изображения из камня, кости, рога и глины; кремневая скульптура; гравированные изображения; графические изображения птиц на сосудах; семантика образа птицы; миф о ныряющей утке; сравнительный анализ.

В своей статье 1972 г. об изображениях водоплавающей птицы в неолитическом искусстве Н.Н. Гурина охарактеризовала их хронологию, территорию распространения и особенности изображений. Используя находки Севера Европейской части СССР вплоть до Урала, она предлагает реконструкцию общей картины мира. При этом Урал является самым восточным районам распространения изображений водоплавающей птицы, отмеченный лишь немногочисленными находками [1, с. 36-45].

За прошедшие почти 50 лет рассмотренная Н.Н. Гуриной источниковая база сильно изменилась. В работе Н.Н. Гуриной Урал представлен только деревянной скульптурой Горбуновского и Шигирского торфяников [1, рис. 9: 4-10]. Скульптурные изображения птиц из камня, кости и глины на Урале еще были неизвестны. Автор настоящей статьи восполняет этот пробел и дополняет территорию Урала новыми материалами, что подтверждает представленную Н.Н. Гуриной картину.

Знакомство с текстом статьи Н.Н. Гуриной показывает, что в ней рассматриваются изображения не только неолита, но и раннего металла (энеолита). Причем из-за немногочисленности источниковой базы скульптурных поделок исследователь анализирует в основном изображения водоплавающих птиц на глиняных сосудах [1, с. 36-37].

К настоящему времени на территории Урала выявлено не менее 35 скульптурных изображений птиц из дерева (рис. 1: 1, 3-8) [2, с. 83-84]. Из новых находок на Горбуновском торфянике нужно отметить ковш с ручкой в виде «трубящего» лебедя (рис. 1: 8). Это крупное изделие высотой около $21 \mathrm{~cm}$ вырезано из комлевой части сосны. В результате древесные слои на шее птице и на ее голове расположены почти перпендикулярно друг другу. Благодаря этому мастер смог реалистично передать оперение птицы и на тулове, и на вытянутой шее. А вот голова лебедя оформлена всего несколькими срезами [3, с. 200]. К находкам с Горбуновского и Шигирского торфяников добавились скульптуры птиц с Кокшаровского и Карасьеозерского торфяников. На Кокшаровско-Юрьинской I стоянке найдена отломанная рукоятка ковшика в виде головки уточки (рис. 1: 1). Головка птицы изображена очень реалистично и мастерски. Клюв уточки от головы отделен резной линией, складки клюва обозначены двумя линиями, на носике клюва неглубокими ямками показаны ноздри. Вся головка утки покрыта мелкими срезами, передающими оперенье [2, с. 83-84].

Скульптуры двух птиц с энеолитического слоя стоянки Разбойничий Остров (Карасьеозерский тор- фяник) выполнены совсем в другом стиле. Они не связаны с посудой и являются полнофигурными изображениями, скорее всего, птиц в полете. Длина почти целой скульптуры достигает $40 \mathrm{~cm}$. Длинная (32 см) шея заканчивается схематически изображенной головкой. На спинке тулова нанесены десять рельефно выраженных поперечных нарезок. От боков тулова в виде небольших выступов отходят слабо обозначенные крылья. С двух сторон выступов прорезаны противолежащие пазы, в которые, по мнению Н.М. Чаиркиной, могли вставляться берестяные или кожаные крылья [4, с. 240, рис. 62: 3]. Однако крылья из птичьих перьев смотрелись бы эффектней. От второй фигурки сохранилось только тулово и часть шеи.

Изображения головок водоплавающих птиц присутствуют и на четырех типах рукояток весел. Все они предельно стилизованы, чаше всего изготовлены в виде уплощенного и расширенного клюва [5, с. 233 , рис. 1: 4-7].

Количество видов водоплавающих птиц разные исследователи определяют по-разному. Среди определимых изображений С.Н. Погорелов выделяет 15 уток, 3 гусей, 5 лебедей и 1 болотную курочку [6, c. 182]. Е.А. Кашина и Н.М. Чаиркина среди птиц, украшающих ложки-ковши, определяют 2 лебедей, по 5 уток и гусей, 1 гагару, 1 гуся или лебедя и 7 неопределимых фигур [7, с. 165].

Вопрос о датировке ложек-ковшей с рукоятями в виде головок птиц полон противоречивости. По традиции эти интересные изделия датируют в пределах неолита - бронзы. Но по стратиграфическим наблюдениям большую часть этих изделий следует отнести к энеолиту.

Если каменная и костяная скульптура из-за единичности находок в работе Н.Н. Гуриной только упоминается, то сейчас на Урале известно 11 скульптур из камня, 10 - из кости и 4 - из глины.

Одна скульптура происходит из дореволюционных раскопок стоянки Коптяки 9, расположенной на Еловом острове Исетского озера (окрестности г. Екатеринбург). О.П. Ченченкова называет ее фалломорфным сапожковидным терочником. Длина изделия 10,7 см, высота - 15,5 см. В профиль изделие очень напоминает изображение плывущей водоплавающей птицы, а именно - лебедя (рис. 1: 2). Тулово у нее овальное в плане и полукруглое в сечении. Вытянутая длинная шея заканчивается отклоненной кверху конической головкой. Изображение очень похоже на деревянную скульптуру «трубящего лебедя» из раскопок В.Ф. Старкова на VI разрезе Горбуновского торфяника (рис. 1: 8). Скульптура орнаментирована короткими насечками: на передней части 
Сериков Ю.Б.

Образ водоплавающей птицы в искусстве нео-энеолитического населения. .

07.00.00 - исторические науки и археология

шеи «елочкой» нанесено 8 рисок, а на боковой - еще 5. В коллекции памятника присутствует керамика от энеолита до раннего железного века [8, с. 286]. Но по стилю изображения скульптуру можно отнести к раннему металлу.

На площади энеолитического Кара-Якуповского поселения (Республика Башкортостан) в разрушенном в погребении № 5 обнаружено две фигурки уточек, выточенные из зеленого сланца (рис. 2: 1, 2). Их высота 4,5 и 5,1 см. Уточки имеют плавные очертания, маленькую головку, толстую шею и массивное тулово. В верхней части тулова просверлены отверстия для подвешивания [9, с. 43-58].

Оставшиеся скульптурные изображения водоплавающих птиц изготовлены из кремневых пород. В Приуралье выявлено 3 скульптуры: 1 в Северном и 2 в Среднем, 5 скульптур происходит из Среднего Зауралья. Только одна скульптура водоплавающей птицы с озера Таватуй (Свердловская обл.) обработана по всей поверхности плоской двусторонней ретушью (рис. 2: 3). У хвоста уточки присутствуют две неглубоких противолежащих выемки, которые служили для пришивания скульптуры на одежду. Все остальные изображения птиц обработаны по периметру краевой ретушью. Полная фигурка утки происходит с энеолитического поселения Варжа (р. Луза, Кировская обл.) (рис. 2: 7). На Аятском Правобе- режном поселении (оз. Аятское, Свердловская обл.) найдено две скульптуры птицы - одна целая и одна с отломанной головкой. Целая фигурка утки изготовлена из первичного отщепа кремнистого сланца. Нижняя часть отщепа обработана крутой ретушью. А по верхней части изделия по всему периметру нанесена мелкая краевая ретушь, которая выделяет головку птицы, шею и слегка выгнутую спинку (рис. 2: 5). У фигурки с отломанной головкой один из предыдущих сколов очень похож на прижатое к телу крыло птицы (рис. 2: 4). Из энеолитического комплекса стоянки Юрьино VII (Юрьинское озеро, Свердловская обл.) происходит фигурка утки, изготовленная из отщепа молочного кварца. Почти по всему периметру она обработана мелкой краевой ретушью (рис. 2: 6). Самая крупная и массивная скульптура птицы размером $5,1 \times 2,3 \times 0,8 \mathrm{~cm}$ обнаружена в энеолитическом культовом центре на Шайтанском озере (Свердловская обл.). К сожалению, у нее также отломана головка. Сильно вытянутая шея позволяет видеть в фигурке изображение лебедя (рис. 2: 8). Отломанная головка птицы сохранилась в неолитическом комплексе поселения Ботыли IV (Республика Удмуртия) [2, с. 21]. Из недавних находок следует упомянуть фигурку уточки из поздненеолитического комплекса поселения Чашкинское озеро IV (Пермский край) (устное сообщение Е.Л. Лычагиной).

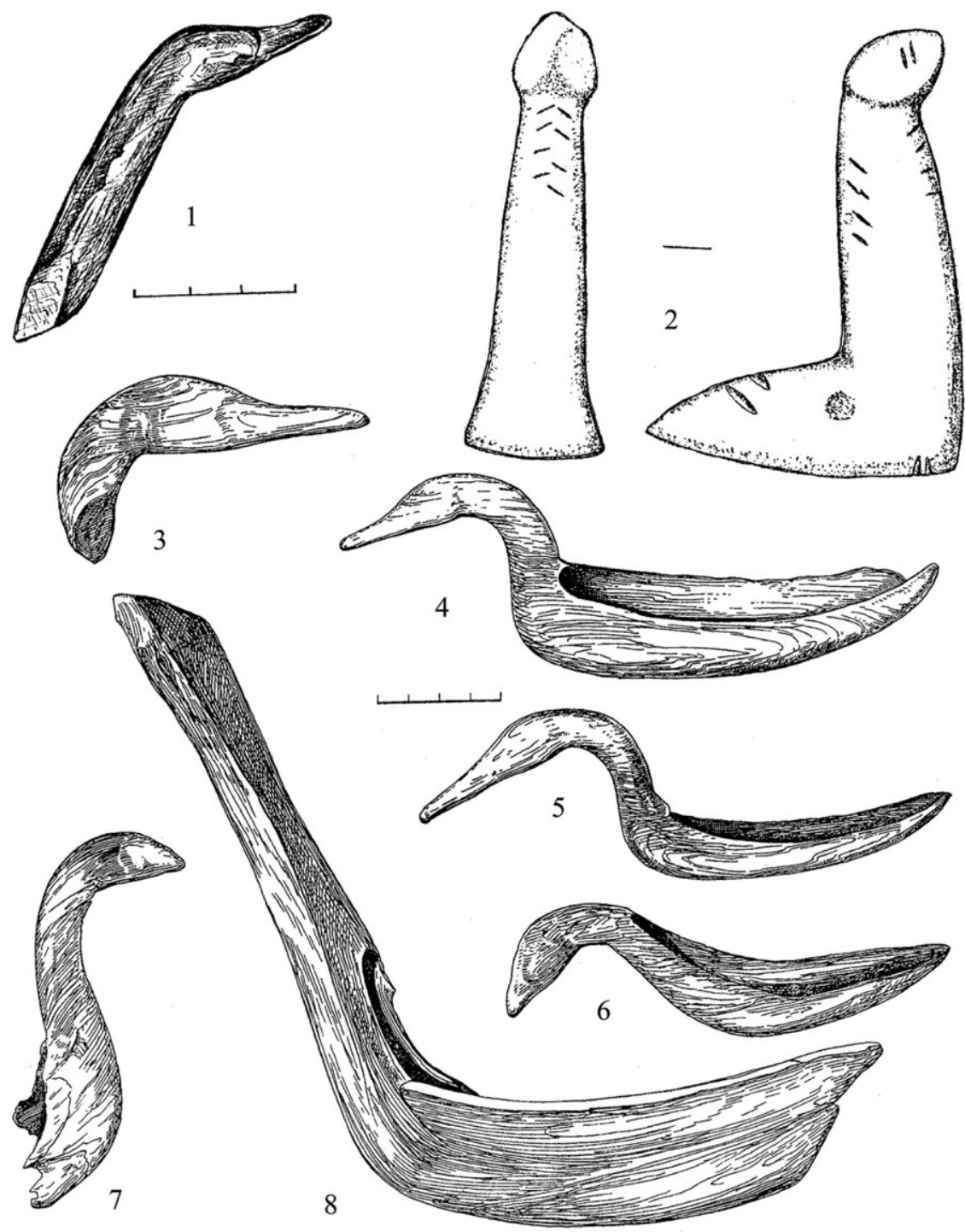

Рисунок 1 - Скульптурные изображения птиц из дерева (1, 3-8) и камня (2) ( 1 - Кокшаровско-Юрьинская I; 2- Коптяки 9; 3-8-6-й разрез Горбуновского торфяника) 

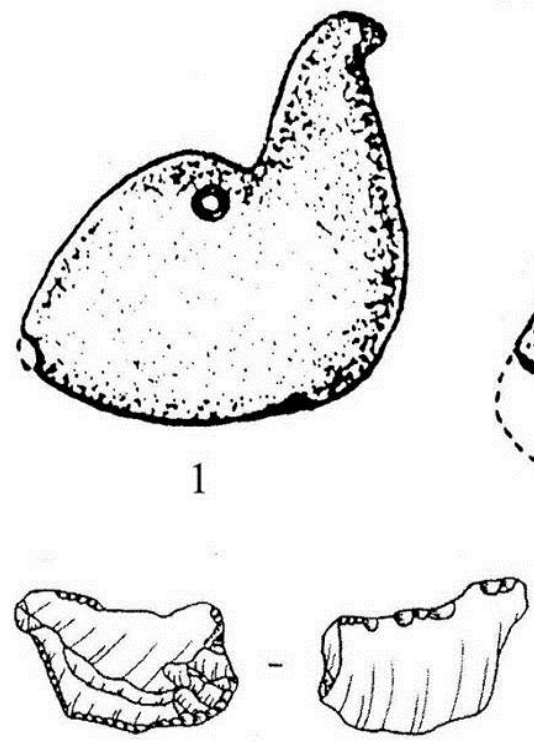

6

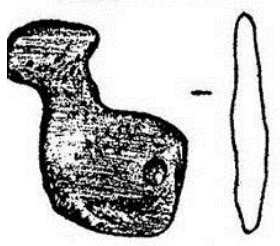

9

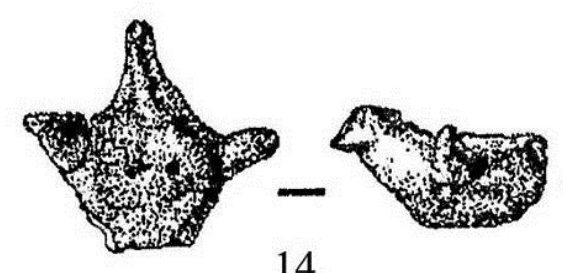

14

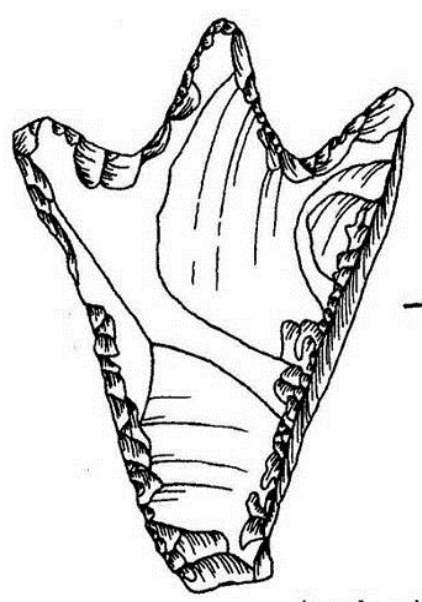

17

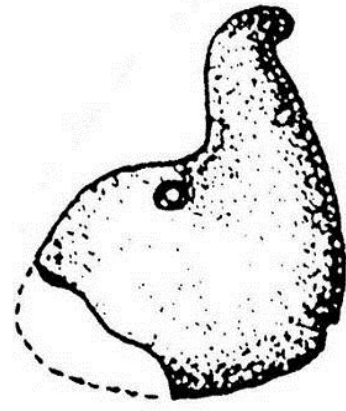

2

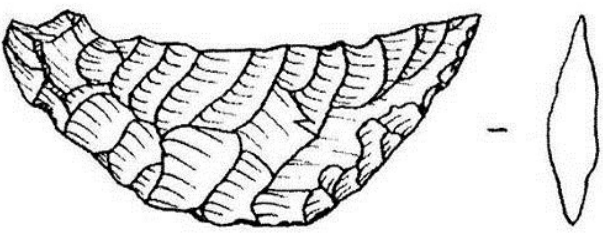

3

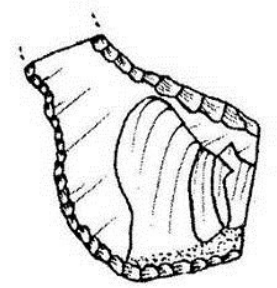

4

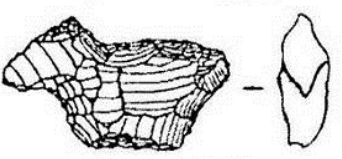

7

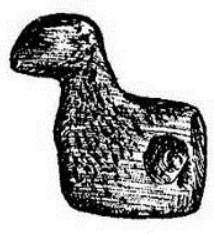

11

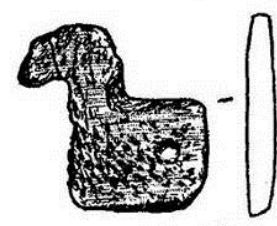

12

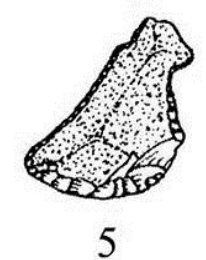

5

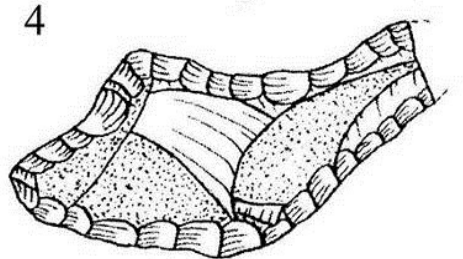

8

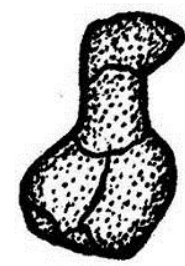

13
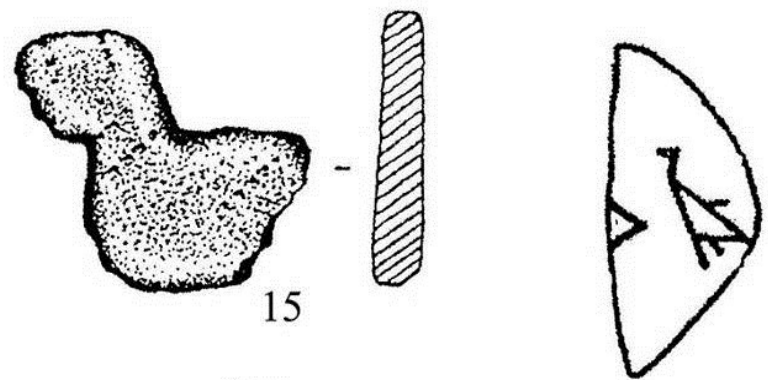

16
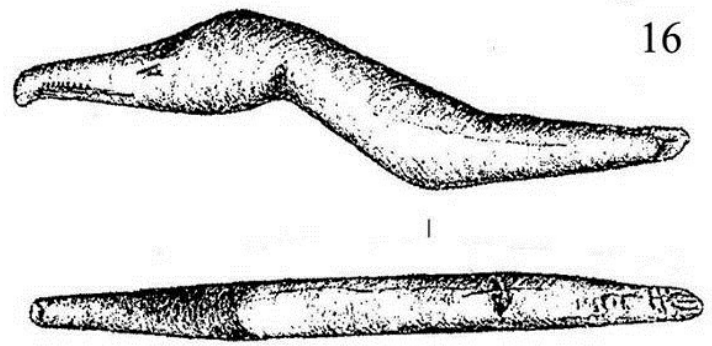

18

Рисунок 2 - Скульптурные $(1-15,17,18)$ и графическое (16) изображения птиц из камня $(1-8,16,17)$, кости (9-12), глины (13-15) и рога (18) (1, 2- Кара-Якуповское; 3- Таватуй VI; 4, 5-Аятское

Правобережное; 6- Юрьино VII; 7- Варжа; 8, 15 - Шайтанское озеро I; 9-12 - грот в камне Дождевом; 13- Пезмогты 3; 14 - Малый Шарташ III; 16- Сутырское; 17- Сабакты 8; 18- дно Шигирского озера)

Условно в эту категорию изделий включено крупное каменное изделие, изготовленное в виде гусиной (?) лапы. Найдено оно в энеолитическом комплексе стоянки Сабакты-8 на озере Сабакты в Башкирском Зауралье. Изготовлено изделие из отщепа серо-зеленой яшмы размером $10,8 \times 7,9 \times 2,1 \mathrm{~cm}$.
Своими очертаниями изделие напоминает лапу водоплавающей птицы и, по мнению В.Г. Котова, могло являться ее символом (рис. 2: 17) [10, с. 17-18].

Изображения водоплавающих птиц, изготовленные из кости и рога, представлены 10 экземплярами. Девять отшлифованных подвесок в виде уточек 
украшали одежду погребенного шамана в гроте на камне Дождевом (р. Чусовая). Все фигурки довольно стандартизированы: они имеют подквадратное тулово, короткую шею и массивную голову. У двух из них сзади головы присутствует своеобразный гребень. Длина уточек 2,2-2,5 см, высота - 2,3-2,5 cм, толщина - 0,3 см (рис. 2: 9-12). От одной уточки сохранилась только головка. У хвостов фигурок каменным сверлом путем встречного сверления проделаны отверстия диаметром 0,2-0,4 cм. Погребение датируется эпохой неолита [11, с. 136].

Скульптура большого крохаля, выполненная из рога, найдена во время подводных археологических исследований на дне Шигирского озера (рис. 2: 18). Скульптура имеет коленчатую форму, скорее всего она являлась рукояткой составного ковшика. Ее длина $-15,8$ см, высота - до 2,2, толщина 1,3 . Клюв птицы довольно вытянут. С одной стороны серией насечек показана ноздря. Хорошо обозначен разрез клюва, конец подклювья загнут книзу. На подклювье с двух сторон нанесены раздельные насечки - 9 и 10 шт. Головка птицы тщательно отшлифована [2, c. 74]. Наиболее вероятная дата данной находки эпоха энеолита.

На полу неолитического жилища поселения Кокшаровское Поле, расположенного на берегу Юрьинского озера, залегала фрагментированная глиняная скульптура птицы. Голова и задняя часть тулова отсутствуют, в нижней части тулова имеется отверстие глубиной до 1,5 см и диаметром 4 мм. Длина сохранившейся части составляет 5,3 см, высота - 4,6 cм, толщина $-2,8$ см. Изготовлена фигурка из плохо высушенного и неравномерно обожженного глиняного теста.

Оригинальная глиняная скульптурка водоплавающей птицы найдена на многослойном поселении Малый Шарташ III (оз. Малый Шарташ, Свердловская обл.). Ее длина составляет 2,7 см, ширина без крыльев - 1,6 см, с крыльями - 3,2 см, толщина 1,1 см. Тулово фигурки имеет уплощенную подовальную форму. Удлиненная шея слегка приподнята и заканчивается маленькой головкой с четко выраженным клювиком. Также приподняты и раскинуты в стороны небольшие крылья конической формы (рис. 2: 14). Авторы находки относят скульптуру к эпохе неолита.

Глиняная скульптура птицы (скорее всего, уточки) обнаружена в комплексе среднего неолита в жилище стоянки Пезмогты 3 (Республика Коми). Она была найдена в разбитом состоянии и реставрирована после раскопок. Изображение птички выполнено достаточно примитивно: вылеплены только тулово и голова, крылья показаны едва заметными выступами (рис. 2: 13). Высота уточки 2,8 см, длина тулова $1,9 \mathrm{~cm}$.

Три уникальные глиняные фигурки (утки, лосихи и рыбы), выточенные из фрагментов керамики, обнаружены в энеолитическом комплексе культового центра Шайтанское озеро I (Свердловская обл.). Они изготовлены из стенок керамических сосудов путем пришлифовки боковых краев. Фигурка уточки сохранилась почти полностью, отсутствует только кончик хвоста (рис. 2: 15). Высота скульптуры $3,1 \mathrm{cм}$, длина сохранившейся части $-3,7$ см. Рекон- струируемая длина - около 4,5 см. Изображение уточки несколько необычно: у нее массивная голова, практически отсутствует шея. Такая техника изображения связана, по-видимому, со свойствами керамического сырья. Из стенки керамического сосуда трудно выполнить фигурку птицы или животного с изображением тонких деталей [2, с. 55-60].

В группу глиняных изделий отнесен и керамический ковшик со сливом в виде головы птицы, найденный на энеолитическом поселении Атымья IV (север Свердловской обл.). Края ковшика с двух сторон орнаментированы гребенчатым штампом, верхняя треть его украшена орнаментом в виде стилизованных птичек (V), а округлое дно - ромбами, выполненными гребенкой (рис. 3: 4).

Единственным изделием представлено гравированное на камне изображение утки. Изображение выгравировано на сломанной сланцевой подвеске, найденной на энеолитическом Сутырском поселении (Республика Марий Эл). На подвеске сохранилась полная фигура утки и, видимо, хвостик второй птицы $[12$, с. 161]. Тулово и головка утки переданы треугольниками, шея, лапки и крылья показаны короткими линиями (рис. 2: 16).

Значительно больше известно графических изображений птиц на керамических сосудах. Количество таких сосудов уже превышает сотню. Чаще всего на керамическую посуду наносились графические изображения водоплавающих птиц. Они известны на всей территории Урала. Самым ранним, по-видимому, является керамический сосуд из поздненеолитического жилища поселения Вис II. От него сохранилось три фрагмента с изображениями водоплавающих птиц. Оттисками гребенчатого штампа показаны плывущие друг за другом утки [13, с. 18 , рис. $3: 2,3]$.

В эпоху энеолита количество сосудов с графическими изображениями птиц резко возрастает. Обычно на сосудах изображались горизонтальные пояса из плывущих птиц. Туловище уточки изображалось тремя (редко - двумя) параллельными отпечатками гребенчатого штампа. Перпендикулярно или слегка под углом к нему таким же отпечатком показана шея. От шеи под прямым углом отходил еще один короткий отпечаток штампа, обозначающий голову уточки. Такие изображения выявлены на керамической посуде Аятского Правобережного, Бараньего мыса, Береговой I, Палатках I, Шайтанском озере I, Шигирском городище, Юрьино IV и др. (рис. 3: 2, 3, 8). Иногда шея птицы оформлялась двумя параллельными линиями гребенки. В редких случаях ниже тулова двумя коротенькими отпечатками штампа показывались ноги птицы.

Гребенчатым штампом выполнялись и более сложные фигуры птиц. В технике «шагающей гребенки» изображены уточки на сосудах с поселений Нижняя Макуша и Чебаркуль I. Прямоугольное тулово птиц с Чебаркуля I заполнено «шагающей гребенкой». Поверх спины расположен горизонтальный ряд из круглых наколов. Голова и шея показаны сдвоенными линиями. Такими же линиями обозначены и ноги, число которых достигает четырех (рис. 3: 5). Следует отметить, что в разных публикациях рисунки фигур на сосуде с Чебаркуля I различаются в деталях. 

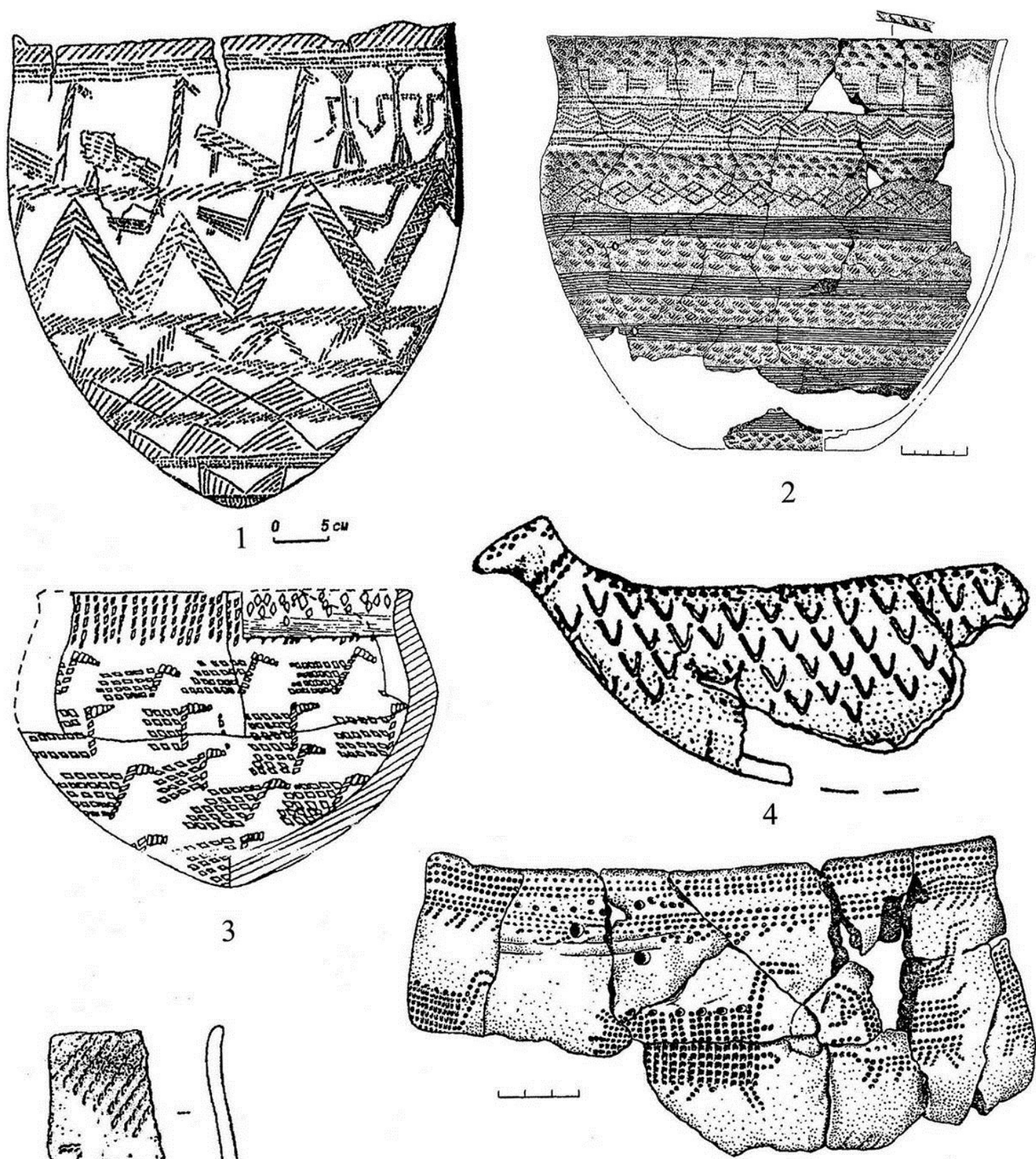

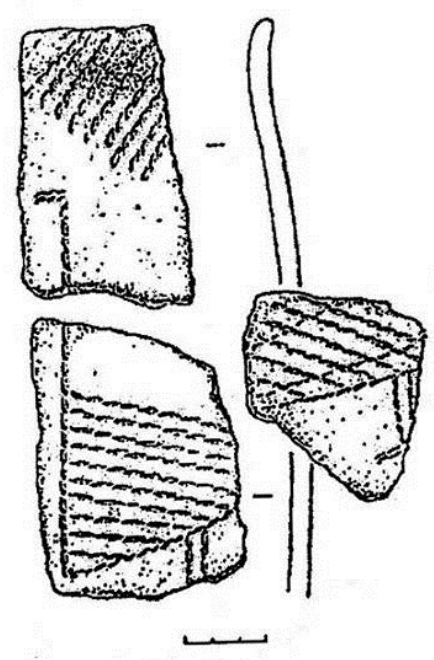

6

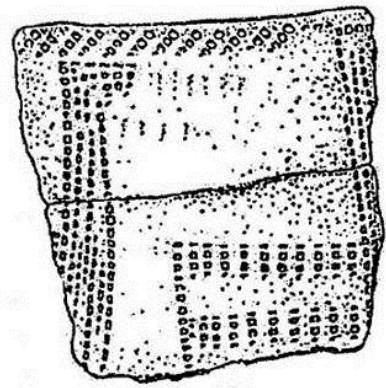

7
5

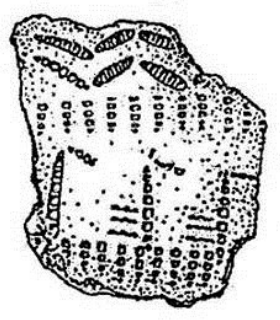

8

Рисунок 3 - Графические изображения птиц на керамических сосудах (1 - Палкино I; 2- Шайтанское озеро I; 3- Ишкиновка 1; 4-Атымья IV; 5- Чебаркуль I; 6- Разбойничий остров; 7-8-Аятское Правобережное)

Уточки с Аятского Правобережного поселения имеют большие размеры, туловище заполнено несколькими горизонтальными рядами отпечатков гребенчатого штампа, также гребенкой образованы толстая шея и массивная голова (рис. 3: 7). Птицы с массивным туловом выявлены и на сосуде с Палкино I.
Также с Палкино I происходит раздавленный сосуд, на котором присутствует целая композиция из антропоморфных и орнитоморфных фигур. Фигуры птиц расположены на сосуде двумя ярусами. В верхнем ярусе напротив антропоморфов нанесены крупные изображения птиц, на нижнем - меньшие по 
размеру. Птицы изображены с длинными шеями (лебеди?), вытянутым прямоугольным или трапециевидным туловом и выступающими ногами. Причем все они находятся в наклонном положении - грудь опущена, а хвост приподнят (рис. 3: 1). Возможно, это поза ныряющей птицы. По мнению В.Д. Викторовой, на сосуде изображены гагары, ныряющие в воды мирового океана за кусочком суши [14, с. 146].

В этом плане представляет интерес фрагмент сосуда с изображениями двух птиц со стоянки Юрьино IV. Оба изображения фрагментированы, от одного сохранилась передняя часть, от другого - задняя. Но это как раз и дает возможность реконструировать полное изображение птицы. Оно выполнено сдвоенными отпечатками гребенчатого штампа. Тулово и шея уточки обозначены длинными отпечатками штампа, голова - короткими (рис. 62: 7). Корпус утки наклонен вперед, что создает впечатление ныряющей птицы. Отличаются от типичных орнитоморфных изображений птицы с Разбойничьего острова. Их крупные фигуры (до 14 см высотой) выполнены в отступающе-накольчатой технике, характерной для липчинской культуры. У птиц длинная шея, треугольное тулово и длинные ноги с лапками (рис. 3: б). Некоторые исследователи предполагают, что они изображают стоящих гусей [15, с. 45].

Известны изображения птиц, образованные неглубокими ямочками. Уточка на сосуде с Палкино I изображена при помощи наколов, сочетания которых имитируют оттиски гребенчатого штампа. На сосуде с Юрьино IV между двумя горизонтальными поясами из шагающей гребенки находятся две фигуры, выполненные круглыми наколами. Одна из фигур, возможно, изображает водоплавающую птицу. Также к энеолиту относятся предельно стилизованные изображения уточек со стоянки Юрьино IV. Они образованы тремя оттисками гребенчатого штампа, образующими короткий зигзаг. Подобные изображения, только выполненные не гребенкой, а сплошной линией, будут широко представлены в материалах поздней бронзы и раннего железа. Например, на VI разрезе - культовом памятнике Горбуновского торфяника - найдено свыше ста керамических тарелок со стилизованными орнитоморфными изображениями [16, с. $68-80$, рис. $1-10]$.

К местной энеолитической традиции уральские исследователи относят фризы из реалистически выполненных изображений водоплавающих птиц на сосудах коптяковской культуры бронзового века. Такие сосуды известны на Верхней и Нижней Макуше, Коптяках 5, Палатках I, Шайтанском озере II (рис. 3: 2) $[17$, с. $49-54]$.

Новые источники подтверждают предположение Н.Н. Гуриной, что территория распространения изображений водоплавающей птицы совпадает с областью проживания населения финно-угорской языковой группы [1, с. 45].

В ранних работах с публикациями орнитоморфных фигур вопросы семантики данных изображений вообще не затрагивались [18, с. 70-73; 19, с. 60-63]. Исключением является статья Н.Н. Гуриной, которая в очень осторожной форме указала на возможную связь водоплавающей птицы с мифом о происхождении Вселенной из яйца утки [1, с. 44]. С увеличением источниковедческой базы количество работ, пытающихся объяснить семантику изображений водоплавающих птиц на сосудах, заметно возрастает.
Современные исследователи считают, что образ птицы выступал в разных символических значениях. Некоторые уральские исследователи образ водоплавающих птиц связывали с образом горы (осью мироздания). При этом водоплавающая птица выступала в качестве основного персонажа в творении мира [15, c. 40-61]. Н.М. Чаиркина поддерживает эту версию, но подчеркивает «чрезвычайно сложный комплекс представлений, связанных с водоплавающей птицей» $[4$, с. 243-244]. И.В. Усачева обилие изображений водоплавающих птиц в энеолите связывает с тотемизмом, а также со становлением промыслового культа [20, с. 116-118]. В.Д. Викторова с коллегами продолжает искать в угорской мифологии новые сведения, характеризующие роль водоплавающей птицы в сотворении земли [21, с. $10-11]$. В.Т. Ковалева отрицает подобные построения и предлагает свое видение орнитоморфных изображений на сосудах: композиции из плывущих друг за другом птиц, по ее мнению, можно связать с календарной символикой. Причем в некоторых композициях она предполагает «даже не мифологический сюжет, а повествование» $[22$, с. 76-77; 23, с. 53-56]. Более взвешенной автору представляется точка зрения, что «на сегодняшний день правильнее ограничиться констатацией фактов и осторожными предположениями, нежели перечислять всевозможные варианты» [24, с. 13].

\section{Список литературы:}

1. Гурина Н.Н. Водоплавающая птица в искусстве неолитических лесных племен // Краткие сообщения Института археологии. Вып. 131. М.: Наука, 1972. C. $36-45$.

2. Сериков Ю.Б. Очерки по первобытному искусству Урала. Нижний Тагил: НТГСПА, 2014. 268 с.

3. Старков В.Ф., Хотинский Н.А., Алексашенко А.А., Калинина И.В. Раскопки на Горбуновском торфянике // Археологические открытия 1978 года. М.: Наука, 1979. С. 200.

4. Чаиркина Н.М. Энеолит Среднего Зауралья. Екатеринбург: УрО РАН, 2005. 313 с.

5. Погорелов С.Н. Весла из торфяниковых памятников Среднего Урала // Вопросы археологии Урала. Вып. 23. Екатеринбург: Изд-во УрГУ, 1998. С. 228-240.

6. Погорелов С.Н. Скульптурные навершия изделий из органики (по материалам торфяниковых памятников Среднего Урала) // Древности Горбуновского торфяника. Охранные археологические исследования на Среднем Урале. Вып. 6. Екатеринбург: Банк культурной информации, 2010. С. 182-185.

7. Кашина Е.А., Чаиркина Н.М. Деревянная посуда с навершиями в виде голов водоплавающих птиц на территории Зауралья, лесной зоны Восточной и Северной Европы // Вестник Новосибирского государственного университета. Серия: История, филология. 2011. Т. 10, вып. 7: Археология и этнография. C. $157-169$.

8. Ченченкова О.П. Каменная скульптура лесостепной Азии эпохи палеометалла III-I тыс. до н.э. Екатеринбург: Изд-во «Тезис», 2004. 336 с.

9. Морозов Ю.А. Кара-Якуповская энеолитическая стоянка // Эпоха меди юга Восточной Европы. Куйбышев, 1984. С. 43-58.

10. Котов В.Г., Савельев Н.С. Энеолитическая стоянка Сабакты-8 в Башкирском Зауралье // Уфимский археологический вестник. 2007. № 6-7. С. 12-18. 
11. Сериков Ю.Б. Исследование грота на камне Дождевом (р. Чусовая) // Вопросы археологии Урала. Вып. 21. Екатеринбург: УрГУ, 1993. С. 120-143.

12. Никитин В.В. Каменный век Марийского края. Йошкар-Ола: МарНИИ, 1996. 177 с.

13. Буров Г.М. Искусство Крайнего Северо-Востока Европы в эпоху неолита - раннего металла и его семантика // Наскальные рисунки Евразии. Новосибирск: Наука, 1992. С. 14-28.

14. Викторова В.Д. Культовые озерные памятники // Культовые памятники горно-лесного Урала. Екатеринбург: УрО РАН, 2004. С. 144-157.

15. Викторова В.Д., Чаиркина Н.М., Широков В.Н. Гора и водоплавающая птица в мировидении древнего уральского населения // Уральский исторический вестник. 1997. № 4. С. 40-64.

16. Чаиркина Н.М. Глиняные тарелки со стилизованными орнитоморфными изображениями из VI разреза Горбуновского торфяника // Археология, этнография и антропология Евразии. 2013. № 3 (55). С. 68-80.

17. Викторова В.Д. Коптяковская культура в горно-лесном Зауралье // III Берсовские чтения: к 95-летию А.А. Берса и 90-летию Е.М. Берс: мат-лы науч.практ. конф. Сентябрь 1997 г., г. Екатеринбург / отв. ред. Н.Л. Кривоносова. Екатеринбург: Банк культурной информации, 1999. С. 49-54.

18. Эдинг Д.Н. Резная скульптура Урала // Труды Государственного исторического музея. Вып. Х. М., 1940. $104 \mathrm{c}$.
19. Мошинская В.И. О зауральских зооморфных изображениях, связанных с глиняной посудой (К вопросу о древних контактах в уральской среде) // Проблемы археологии и древней истории угров. М.: Наука, 1972. С. 56-65.

20. Усачева И.В. К истокам мировоззрения древних уральцев (по материалам мелкой глиняной и кремневой пластики эпохи неолита - бронзы оз. Андреевского Тюменской обл.) // Вопросы археологии Урала. Вып. 23. Екатеринбург: Изд-во УрГУ, 1998. C. $105-134$.

21. Викторова В.Д., Колмакова В.В., Федорова А.Ю. И разные народы побывали здесь... // Образы и сакральное пространство древних эпох. Екатеринбург: Аква-Пресс, 2003. С. 9-20.

22. Ковалева В.Т. Образ мира населения аятской культуры (по орнаментам на сосудах) // Четвертые Берсовские чтения. Екатеринбург: Аква-Пресс, 2004. C. $76-82$.

23. Ковалева В.Т., З Зырянова С.Ю. О семантике обряда у камня Дыроватого и образа водоплавающей птицы на энеолитической посуде в Зауралье // Проблемы археологии: Урал и Западная Сибирь (к 70летию Т.М. Потемкиной). Курган: Изд-во Курганского гос. ун-та, 2007. С. 50-55.

24. Молодин В.И., Чемякина М.А. Орнитоморфные навершия одиновской культуры (Западносибирская лесостепь) // Уральский исторический вестник. 2010. № 1. C. 5-14.

\section{THE WATERFOWL IMAGE IN THE ART OF THE NEO-ENEOLITHIC POPULATION OF THE URALS} (C) 2019

Serikov Yuri Borisovich, doctor of historical sciences, leading researcher of Archaeological Laboratory Nizhny Tagil State Social and Pedagogical Institute (branch) of Russian State Vocational Pedagogical University (Nizhny Tagil, Sverdlovsk Region, Russian Federation)

Abstract. The first generalizing work on waterfowl images in Neolithic art was presented by N.N. Gurina in 1972. Based on numerous findings the author defines their chronology and distribution area, characterizes the features of images and offers reconstruction of the overall picture of the world. At the same time Ural is the easternmost distribution area of waterfowl images marked by only a few finds. Nowadays the situation presented by N.N. Gurina has changed a lot. On the territory of Ural dozens of Neolithic and Eneolithic sculptural images of waterfowls made of stone, clay, bone, horn and wood were discovered. Even more known are the engraved images of birds on ceramic vessels. Practically all those vessels belong to the Eneolithic time. According to the Ural archeologists the image of the bird appeared in different symbolic meanings: the bird was considered to be the main character in the creation of the world; it could have been demiurge, ancestor and progenitor of the genus; the bird is associated with the development of craft cult; it could reflect the calendar symbols. The assumption of N.N. Gurina that the area of distribution of waterfowl images coincides with the area of residence of the population of the Finno-Ugric language group is confirmed.

Keywords: Ural; waterfowl; duck; goose; swan; loon; marsh hen; Neolithic; Eneolithic; sculptural images of stone, horn and clay; flint sculpture; engraved images; graphic images of birds on vessels; semantics of image of a bird; myth of diving duck; comparative analysis.

УДК 902.01

DOI 10.24411/2309-4370-2019-12217

Статья поступила в редакцию 25.01.2019

\section{АКТУАЛЬНЫЕ ВОПРОСЫ В ИЗУЧЕНИИ РАННЕГО ЭНЕОЛИТА ДОНСКОЙ ЛЕСОСТЕПИ (ХРОНОЛОГИЯ, ПЕРИОДИЗАЦИЯ, СИНХРОНИЗАЦИЯ)}

(C) 2019

Скоробогатов Андрей Михайлович, кандидат исторических наук, начальник археологического отдела ООО «Терра» (г. Воронеж, Российская Федерация)

Аннотащия. Долгое время энеолит Донской лесостепи оставался одной из самых малоизученных эпох в археологической схеме региона. Однако с конца 1960-х годов памятники с материалами эпохи энеолита активно исследуются на территории Воронежской и Липецкой областей. К 1980-м годам у исследователей сложилась концепция развития культур медно-каменного века в рамках мариупольской культурно-исторической области Днепро-Доно-Уральского междуречья, актуальная и в настоящее время. Были обоснованы 